\title{
Amsterdaml'og
}

\section{Geothermal systems as a key component in energy infrastructure - systems and network integration towards a Zero-Emission Power Hub.}

\author{
Andries K.T. Wever ${ }^{1}$, Douglas T. Gilding ${ }^{1,2}$, Karl-Heinz A.A. Wolf ${ }^{1}$,
}

Keywords: Geothermal energy, $\mathrm{CO}_{2}$ injection, $\mathrm{CCS}$, economics, drilling technology, infrastructure integration.

Many countries and companies are developing geothermal systems as a sustainable, secure, and domestic energy source. However, in the Netherlands, with a low thermal gradient, there are no governmental incentives for such developments, making geothermal heat and electricity production at best marginally economic. Therefore smart solutions are needed as to economize geothermal systems, such as integration into existing infrastructure, exploitation of synergies with fossil-fuel based systems, and innovation on well-construction technology.

The Delft Geothermal Project was launched to provide for a demonstration of solutions to these needs. Initiated by students, staff and alumni of the Applied Geotechnology department of TU Delft, it evolved into a broad consortium of commercial, governmental and industrial parties aiming to develop an innovative geothermal system at the TU Delft campus. This system 1 ) is designed for commercial heat production for a grid heating network, 2) will be constructed with innovative drilling technology, and 3) will as well serve as an in-situ laboratory for geothermal measurements and experiments. As such, it provides for an energy production facility, a technology demonstration case, and a research facility.

However, only assessing the system as described above would not honor the most valuable synergies that can be achieved. In the presence of existing gridheating networks, produced geothermal heat can be included in the gross energy mix. As such, a multi-source feeding of the network is achieved improving delivery reliability. By combing geothermal sources with power/heat cogeneration, a peak shaving effect on heat demand can be achieved. By colocating the geothermal system with carbon-based energy systems (such as cogeneration), $\mathrm{CO}_{2}$ can be captured and dissolved in the return water as 'sparkling water' for co-injection, providing a safe and durable $\mathrm{CO}_{2}$ sequestration option. When the geothermal source provides heat of sufficient quality (i.e. sufficient flux and high enough temperature), the heat can be used for electricity production, or can be cascaded through high- and low-temperature grid heating networks.

As such, effective systems and network integration is achieved with a very high degree of flexibility. For this, the Zero-Emission Power Hub concept is proposed: a hub of energy networks and production systems which optimally exploits synergies, provides for back-up production, while minimizing $\mathrm{CO}_{2}$ exhaust into the atmosphere. This way, we believe it is possible to create an economically feasible, environmentally sustainable multipurpose energy system. Enabling technologies for this are being identified and developed: To enable drilling deep geothermal

${ }^{1}$ 1)Delft University of Technology, Stevinweg 1, $2628 \mathrm{CN}$ Delft, The Netherlands

2)Delft Geothermal Project (DAP), Stevinweg 1, 2628 CN Delft, The Netherlands Corresponding author: DAP@tudelft.nl 


\section{Amsterdaml'og}

wells in urban areas with limited operational space, new full composite casing drilling and back of the truck drilling technologies have been developed. As these composite plastic materials are corrosion resistant, $\mathrm{CO}_{2} \mathrm{co}$-injection is feasible when correctly managed for the subsurface. $\mathrm{CO}_{2}$ capture and processing installations will be investigated to come to effective co-injection with the return water. Implementation of heat to electricity will require substantial developments of technology. All these aspects are being defined in the "Research, Education and Development" strategy of the Delft Geothermal Project which will be operated in close cooperation with Delft University of Technology and locally based companies. 